\title{
A Study on 615 Cases of Idiopathic Epistaxis
}

\author{
Tomoko Kida ${ }^{1}$ Hideki Oka ${ }^{1}$ Katsuya Fushimi ${ }^{1}$ Mariko Honda ${ }^{1}$ Junya Fujiki ${ }^{1}$ Kenzo Tsuzuki ${ }^{2}$ \\ ${ }^{1}$ Department of Otolaryngology, Takarazuka City Hospital, \\ Takarazuka, Hyogo, Japan \\ 2 Department of Otolaryngology-Head and Neck Surgery, Hyogo \\ College of Medicine, Nishinomiya, Hyogo, Japan \\ Int J Pract Otolaryngol 2021;4:e21-e28. \\ Address for correspondence Tomoko Kida, Department of \\ Otolaryngology, Takarazuka City Hospital, Hyogo 665-0827, Japan \\ (e-mail: moriko_0109@yahoo.co.jp).
}

\begin{abstract}
Keywords

- epistaxis

- rebleeding

- endoscope
\end{abstract}

\section{Introduction}

Epistaxis, an otorhinolaryngological condition that is commonly encountered in routine treatments, is experienced by approximately $60 \%$ of adults at least once in their lifetime. ${ }^{1-5}$ While hemostasis can be achieved through compression and cauterization in an outpatient treatment in many cases, there are cases where bleeding recurs or hemostasis is difficult, requiring hospitalization and additional surgery. ${ }^{6}$
We clinically examined cases of idiopathic epistaxis treated at our hospital in the past 8 years and have reported the results along with literature research.

\section{Materials and Methods}

A total of 615 cases of idiopathic epistaxis that were treated at our department in 8 years from January 2012 to December 2019 were included. Cases of traumatic injury, postnasal or received

May 22, 2020

accepted

October 9, 2020
DOI https://doi.org/ 10.1055/s-0041-1723788. ISSN 2569-1783.

\footnotetext{
(C) 2021. The Author(s).

This is an open access article published by Thieme under the terms of the Creative Commons Attribution-NonDerivative-NonCommercial-License, permitting copying and reproduction so long as the original work is given appropriate credit. Contents may not be used for commercial purposes, or adapted, remixed, transformed or built upon. (https://creativecommons.org/ licenses/by-nc-nd/4.0/) Georg Thieme Verlag KG, Rüdigerstraße 14, 70469 Stuttgart, Germany
} 
paranasal surgery, tumors, hereditary hemorrhagic telangiectasia, and course observation without bleeding were excluded. Including the cases that were treated by a previous physician, we excluded cases that were in a state of hemostasis at the time of examination, cases without any blood in the nasal cavity, and cases that were not subsequently examined. The present study was conducted in accordance with the Ethics Review Committee of Takarazuka City Hospital (approval number: 20200501).

We retrospectively examined age, sex, time of examination, underlying conditions, site of bleeding, hemostasis method, rebleeding, and hospitalization based on medical records.

The site of epistaxis was diagnosed with anterior rhinoscopy, a digital flexible endoscope, and a rigid endoscope. Pretreatment was performed with a gauze soaked in 5,000-fold diluted adrenaline and $4 \%$ lidocaine. The site of bleeding was confirmed with anterior rhinoscopy. A digital flexible endoscope was used for cases that could not be visually confirmed to confirm the site of bleeding. If additional hemostasis was necessary to confirm the site of bleeding, a rigid endoscope was used. Cases were classified into the following: septum, inferior meatus, inferior nasal concha, middle meatus, middle nasal concha, superior nasal concha, and unknown source of bleeding. We further divided the septum into the Kiesselbach plexus (anterior), olfactory cleft (posterosuperior), and posteroinferior septums. 1,7

-Fig. 1 shows our therapeutic policy for epistaxis. The hemostatic method is as follows: when the site of bleeding could be identified, it was cauterized, and when it could not be identified, compression was used. When compression was used after cauterization, the case was classified as cauterized. For cauterization, electrocoagulation or chemical coagulation was used. For electrocoagulation, monopolar electrodes for coagulation and bipolar forceps from Ellmann-Japan (Osaka, Japan) were used. For chemical coagulation, we used 30\% silver nitrate. For minor bleeding from the Kiesselbach plexus, we used chemical coagulation. For other sites of bleeding, we used electrocoagulation. For compression, we used a $30-\mathrm{cm}$ long gauze with oxytetracycline hydrochloride and hydrocortisone ointment as a nonabsorbent material and an oxidized cellulose patch as an absorbent material. The nonabsorbent material was used for cases with blood flow to the pharynx, and the absorbent material was used for cases without confirmed blood flow. The nonabsorbent material was removed after 3 to 4 days. After-hour examination was defined as examination performed outside of the specified hours at our hospital (17:00-8:30). Rebleeding was defined as additional visit to our department due to bleeding within 7 days of the hemostasis treatment.

For statistical analysis, we used the Student's $t$-test to compare the average from two groups. We used the Fisher's exact test for difference in ratio and $2 \times 2$ contingency table. We used EZR version 1.41 (Saitama, Japan) for the analysis. $p$-Values of $<0.05$ indicated significant difference. Data were presented as mean \pm standard deviation.

\section{Results}

\section{Initial Bleeding Cases (all cases) $(n=615)$}

\section{Patient Background}

The patients' ages ranged from 2 to 101 years (mean age: $66.2 \pm 17.7$ years). For both men and women, 70 s was the most common age group. There were 343 men (55.8\%) and 272 women (44.2\%), indicating that slightly more patients were men (-Fig. 2A).

January had the largest number of patients (86 cases), followed by December (70 cases) and February (64 cases) (-Fig. 2B). We defined spring as March to May, summer as June to August, fall as September to November, and winter

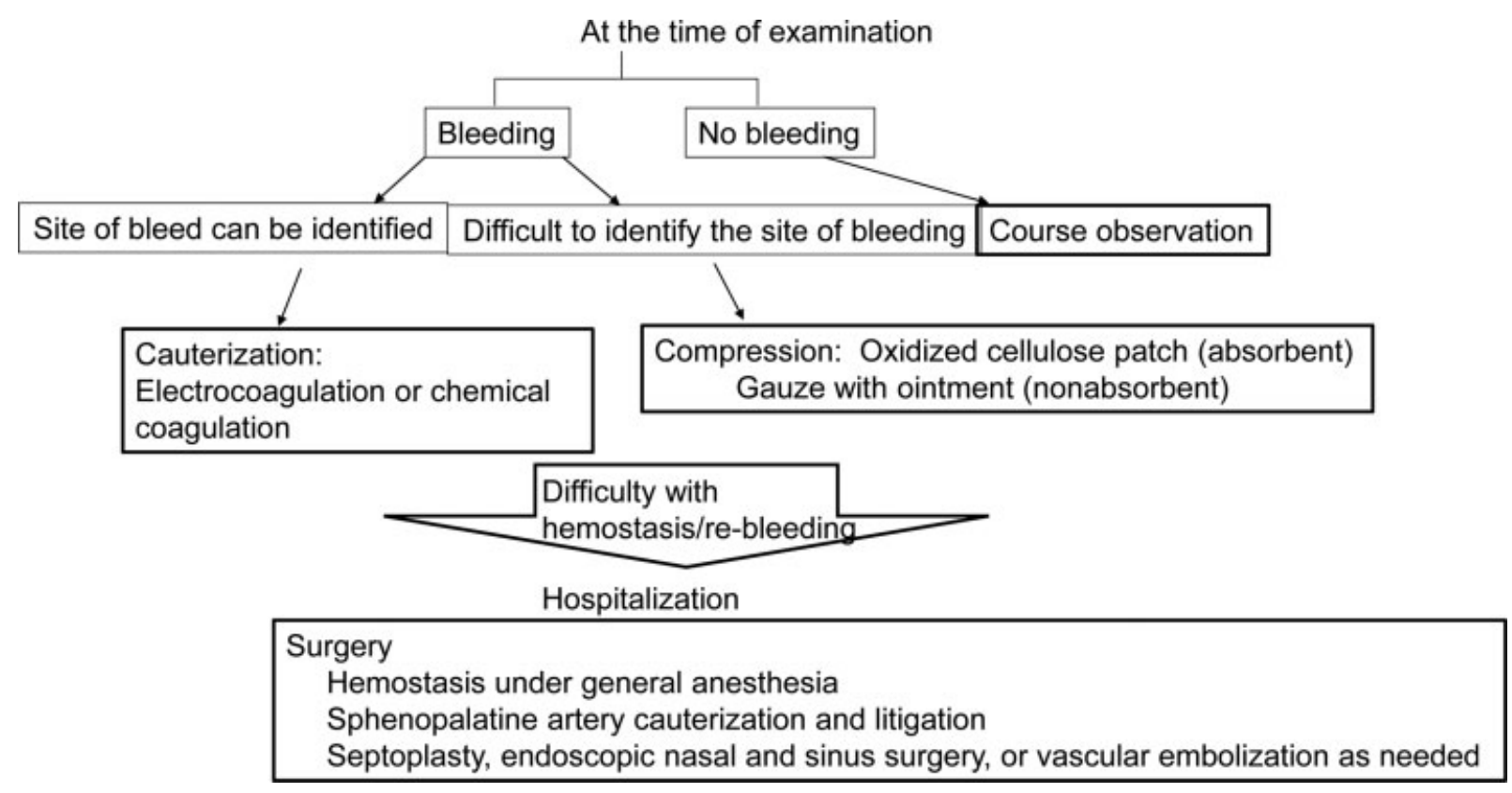

Fig. 1 Treatment policy for epistaxis. 


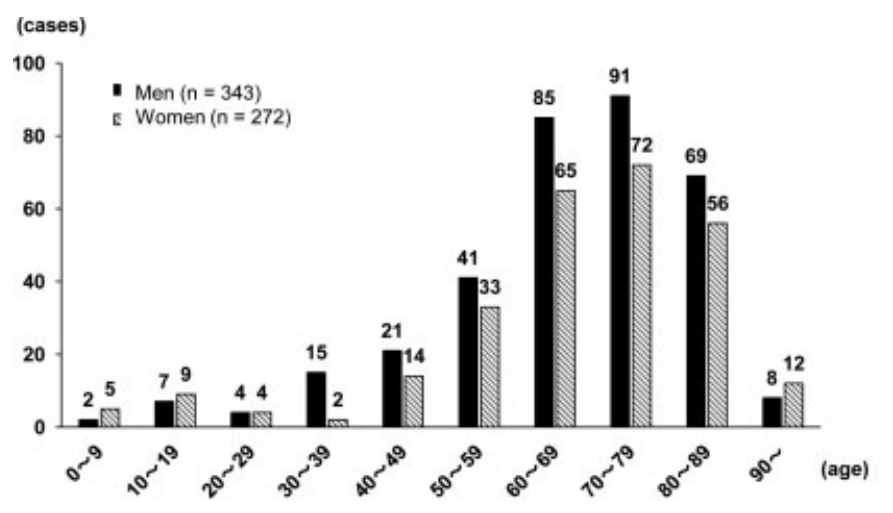

A

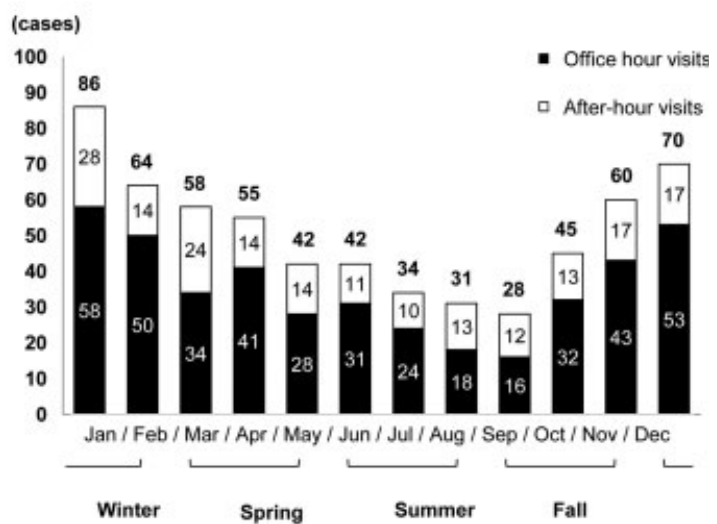

B

Fig. 2 Patient backgrounds. (A) age and sex. The most common age group was 70s, with a majority of men. (B) Visitation time. It was higher in the winter and peaked in January.

as December to February. ${ }^{8}$ Winter had the highest number of cases at $35.8 \%$ (220/615 cases), whereas summer had the lowest number of cases at $17.4 \%$ (107/615 cases). There were 187 cases of after-hour visits (30.4\%, 186/615 cases).

\section{Underlying Conditions}

Underlying conditions were confirmed in $66.0 \%$ of cases (406/615 cases). Hypertension was the most common underlying condition at $34.6 \%$ (213/615 cases), followed by heart disorder at $22.1 \%$ (136/615 cases) (including overlapping cases). There were $28.5 \%$ cases for which antithrombotic agents (antiplatelet drugs and anticoagulants) were used (175/615 cases). There were $6.3 \%$ cases for which the use of antithrombotic agent was discontinued after treatment of epistaxis (11/175 cases) (-Table $\mathbf{1}$ ).

\section{Site of Bleeding}

The Kiesselbach plexus was the most common site of bleeding, accounting for $75.0 \%$ (461/615 cases). There were $7.8 \%$ cases in which the site of bleeding was unknown (48/615 cases) (-Table 2).

\section{Initial Method of Hemostasis}

Hemostasis was performed on $96.9 \%$ (596/615 cases) of cases, where electrocoagulation was most common at $73.0 \%$ (449/615 cases) ( - Fig. 3A). Hemostasis with a rigid endoscope was performed on $10.4 \%$ cases (64/615 cases) of cases. Initial hemostatic treatment achieved hemostasis on 544 cases (-Fig. 3B). Bleeding recurred in $11.5 \%(71 / 615)$ cases (-Fig. 3B). In 3.1\% cases (19/615 cases), a conservative approach involving course observation was selected, and hemostatic treatment was not performed. Among these 19 cases, 17 did not undergo initial hemostatic treatment and experienced rebleeding. There was one case that required hospitalization at a later date and cauterization under general anesthesia due to developmental disabilities. There was another case that experienced a drop in blood pressure, adduction of the eyes, and double vision during the treatment, and required transfer to another hospital. The ocular movement disorder experienced by this case naturally resolved while waiting for the transportation. Detailed examination at another hospital did not reveal any abnormalities, and the patient has not subsequently experienced any ocular movement disorder since then.

Table 1 Underlying diseases (including overlapping cases)

\begin{tabular}{|l|l|l|l|}
\hline Underlying conditions & $\begin{array}{l}\text { Initial bleeding }(\boldsymbol{n}=\mathbf{6 1 5}) \\
\text { Case number (\%) }\end{array}$ & $\begin{array}{l}\text { Rebleeding }(\boldsymbol{n}=\mathbf{7 1}) \\
\text { Case number }(\%)\end{array}$ & $p$-Value \\
\hline Yes & $406(66.0 \%)$ & $53(74.6 \%)$ & 0.11 \\
\hline Hypertension & $213(34.6 \%)$ & $23(32.4 \%)$ & 0.79 \\
\hline Heart diseases & $136(22.1 \%)$ & $25(35.2 \%)$ & $0.009^{\text {a }}$ \\
\hline Diabetes & $57(9.3 \%)$ & $6(8.5 \%)$ & 1.0 \\
\hline Cerebrovascular diseases & $37(6.0 \%)$ & $3(4.2 \%)$ & 0.79 \\
\hline Hematologic diseases & $27(4.4 \%)$ & $3(4.2 \%)$ & 1.0 \\
\hline Impaired liver functions & $25(4.1 \%)$ & $8(11.3 \%)$ & $0.0046^{\text {a }}$ \\
\hline Use of antithrombotic agents & $175(28.5 \%)$ & $43(60.6 \%)$ & $0.037^{\text {a }}$ \\
\hline No & $209(34.0 \%)$ & $19(26.8 \%)$ & $0.012^{\text {a }}$ \\
\hline
\end{tabular}

Note: $p$-Value for the comparison between the initial bleeding group and the rebleeding group using the Fisher's exact test.

aSignificant difference. 
Table 2 Site of bleeding

\begin{tabular}{|c|c|c|c|c|c|}
\hline \multirow[b]{2}{*}{ Site of bleeding } & \multicolumn{2}{|c|}{ Initial bleeding $(n=615)$} & \multicolumn{3}{|c|}{ Rebleeding $(n=71)$} \\
\hline & $\begin{array}{l}\text { Case } \\
\text { number (\%) }\end{array}$ & $\begin{array}{l}\text { Use of } \\
\text { endoscope (\%) }\end{array}$ & $\begin{array}{l}\text { Case } \\
\text { number (\%) }\end{array}$ & $\begin{array}{l}\text { Rate of } \\
\text { rebleeding (\%) }\end{array}$ & $\begin{array}{l}\text { Use of endoscope } \\
\text { for rebleeding (\%) }\end{array}$ \\
\hline \multicolumn{6}{|l|}{ Septum } \\
\hline $\begin{array}{l}\text { Anterior } \\
\text { (Kiesselbach plexus) }\end{array}$ & $461 / 615$ (75.0\%) & $8 / 461(1.7 \%)$ & $24 / 71(33.8 \%)$ & $24 / 461(5.2 \%)$ & $2 / 24(8.3 \%)$ \\
\hline Posterosuperior (cleft) & $26 / 615(4.2 \%)$ & $13 / 26(50.0 \%)$ & $9 / 71(12.7 \%)$ & $9 / 26(34.6 \%)$ & 9/9 (100\%) \\
\hline Posteroinferior & 10/615 (1.6\%) & $6 / 10(60.0 \%)$ & $3 / 71(4.2 \%)$ & $3 / 10(30.0 \%)$ & $3 / 3(100 \%)$ \\
\hline Middle meatus & $20 / 615(3.3 \%)$ & $7 / 20(35.0 \%)$ & $13 / 71(18.3 \%)$ & $13 / 20(65.0 \%)$ & $11 / 13(84.6 \%)$ \\
\hline Inferior nasal concha & $18 / 615(2.9 \%)$ & $5 / 18(27.8 \%)$ & $0 / 71(0 \%)$ & $0 / 18(0 \%)$ & $0 / 0(0 \%)$ \\
\hline Inferior meatus & $17 / 615(2.8 \%)$ & $13 / 17(76.4 \%)$ & $1 / 71(1.4 \%)$ & $1 / 17(5.9 \%)$ & $1 / 1(100 \%)$ \\
\hline Middle nasal concha & $14 / 615(2.3 \%)$ & $7 / 14(50.0 \%)$ & $3 / 71(4.2)$ & $3 / 14(21.4 \%)$ & $2 / 3(66.7 \%)$ \\
\hline Superior nasal concha & $1 / 615(0.2 \%)$ & $1 / 1(100 \%)$ & $0 / 71(0 \%)$ & $0 / 1(0 \%)$ & $0 / 0(0 \%)$ \\
\hline Unknown & $48 / 615(7.8 \%)$ & $4 / 48(8.3 \%)$ & $18 / 71(25.4 \%)$ & $18 / 48(37.5 \%)$ & $6 / 18(33.3 \%)$ \\
\hline
\end{tabular}

Note: Rate of rebleeding is the rate relative to the number of initial bleeding in the same site.
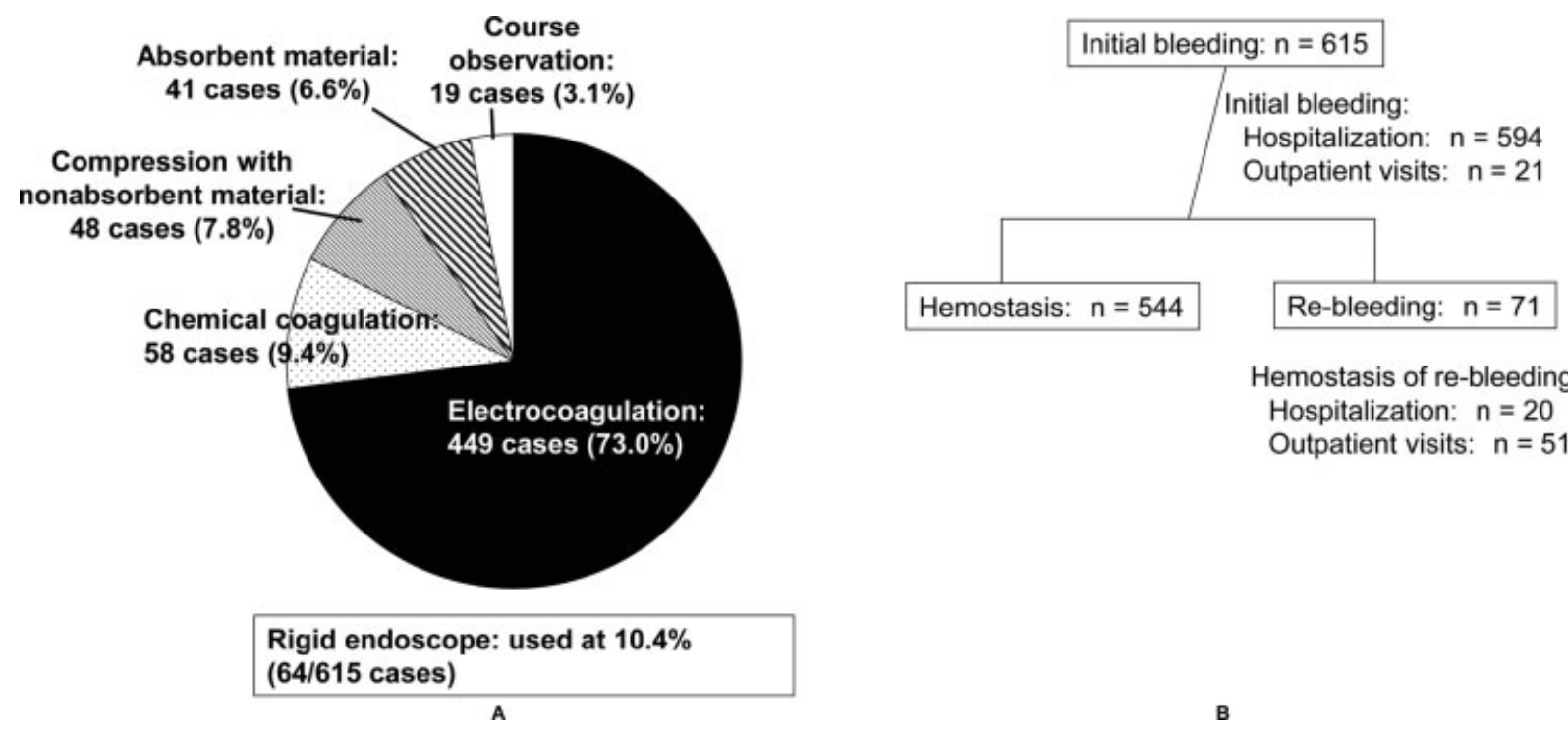

Hemostasis of re-bleeding: Hospitalization: $n=20$

Outpatient visits: $n=51$

Fig. 3 Hemostasis methods. (A) Hemostasis methods for the initial bleeding. The most common method of hemostasis was electrocoagulation, and the use of endoscope was 10.4\%. (B) Initial bleeding $(n=615)$ and rebleeding $(n=71)$.

\section{Rebleeding Cases $(\boldsymbol{n}=\mathbf{7 1})$}

The patients were aged 21 to 95 years (mean age: $68.8 \pm 14.1$ years). There were 50 men $(70.4 \%)$ and 21 women (29.6\%). Compared with the 615 epistaxis cases, there was no significant difference in the mean age, but there were significantly more men $(p=0.01)$. After-hour visits were conducted for $32.4 \%$ (23/71) of cases (-Tables 1 and $\mathbf{2}$ and - Fig. 4).

There was an underlying condition in $74.6 \%$ (53/71) of cases. Heart disease was the most common underlying condition at $35.2 \%$ ( $25 / 71$ cases), followed by hypertension at $32.4 \%$ (23/71 cases) and impaired liver function at $11.3 \%$ (8/71 cases) (including overlapping cases). The use of antithrombotic agents was confirmed in $60.6 \%$ of cases (43/71 cases), out of which seven cases discontinued the use of antithrombotic agents after the treatment of epistaxis. Compared with the total number of patients with epistaxis (615 cases), the number of patients with underlying conditions was high. Specifically, the number of patients with heart disease $(p=0.009)$, impaired liver function $(p=0.0046)$, and the use of antithrombotic agents $(p=0.037)$ was significantly high (-Table 1$)$. Cases who stopped the use of antithrombotic agents after the treatment of the initial hemostasis were significantly more likely to exhibit rebleeding $(p=0.00027)$.

The site of rebleeding was most often the middle meatus $(65.0 \%, 13 / 20$ cases) (- Table 2 ). - Fig. 4 shows the method of hemostasis for rebleeding cases: to treat both the initial bleeding and rebleeding. There were 5.6\% (4/71) cases that experienced rebleeding despite the use of a rigid endoscope. Two had unknown source of bleeding and were compressed with the nonabsorbent material: one had the middle nasal concha confirmed as the source of bleed and was cauterized 


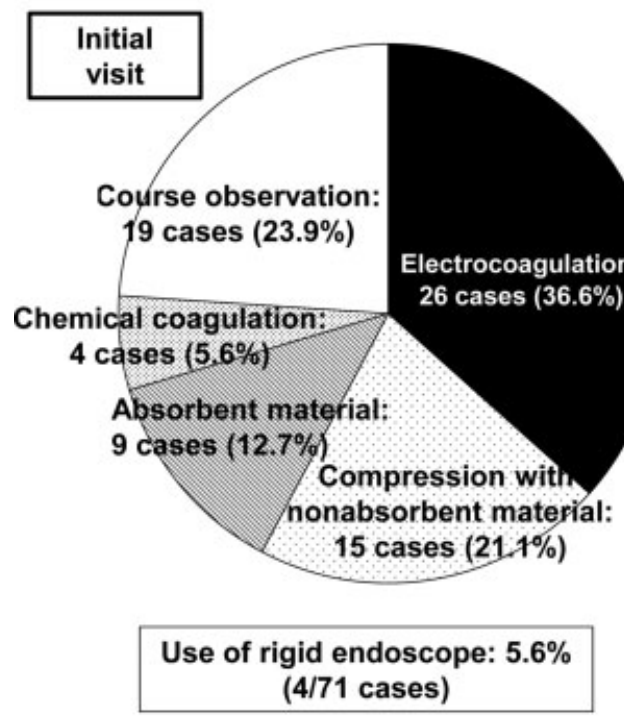

A

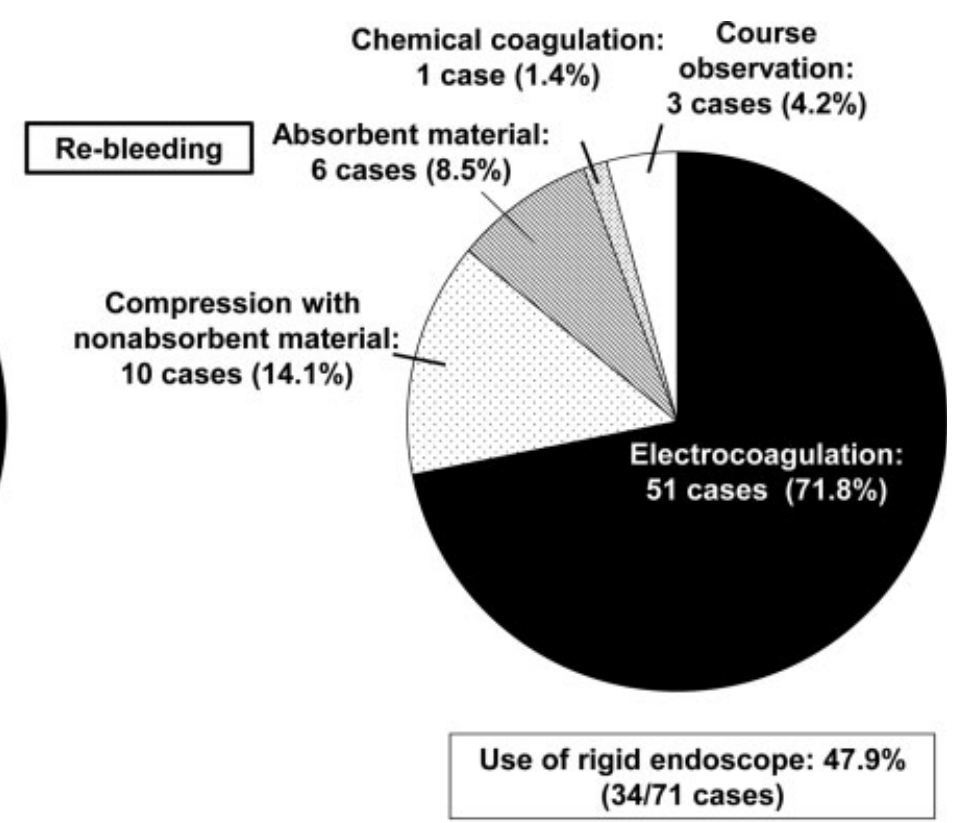

B

Fig. 4 Hemostasis methods for rebleeding cases. (A) Methods of hemostasis for initial bleeding. (B) Methods of hemostasis for rebleeding. For rebleeding cases, electrocoagulation was not often used during the treatment of the initial bleeding. The use of electrocoagulation increased during the treatment of rebleeding.

and another had bleeding from the secondary injury caused by equipment used for the treatment. A total of $47.9 \%$ cases underwent rigid endoscopy use during the treatment of rebleeding (34/71 cases). During the treatment of the initial bleeding in recurring cases, the ratio of the use of compression was relatively high. When treating rebleeding, electrocoagulation was used more often, as was a rigid endoscope. There were $2.8 \%$ cases that required hospitalization and hemostasis under general anesthesia to treat rebleeding (2/71 cases). The site of hemorrhage was the posteroinferior septum for one and unknown for the other. Both cases went under septoplasty with electrocoagulation for the site of bleeding.

\section{Hospitalization Cases $(n=41)$}

A total of $6.7 \%$ cases required hospitalization (41/615 cases). Patients were aged 16 to 95 years (mean age: $65.9 \pm 16.3$ years). There were 29 men (70.7\%) and 12 women (29.3\%). There was no statistically significant difference in mean age and sex compared with the overall epistaxis cases (-Fig. 5).

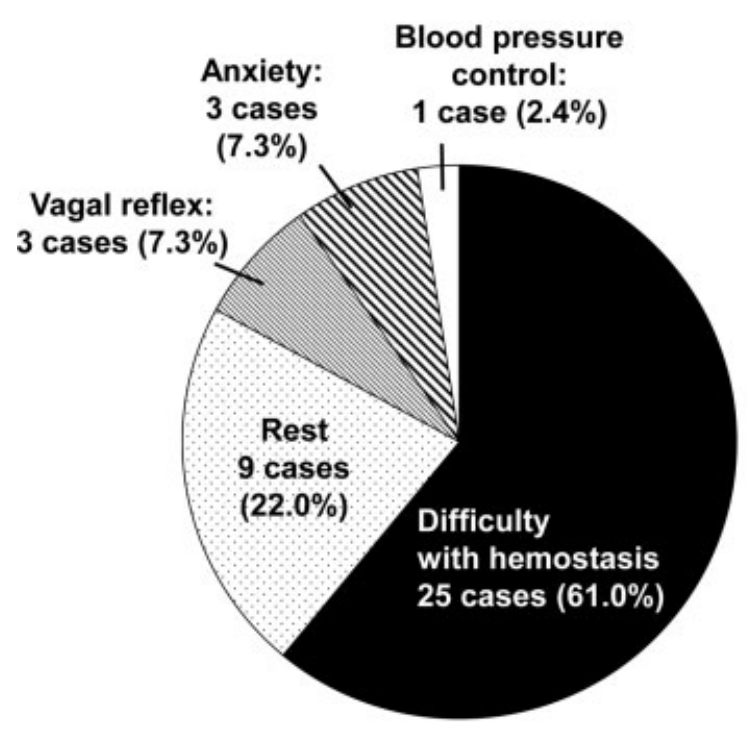

A

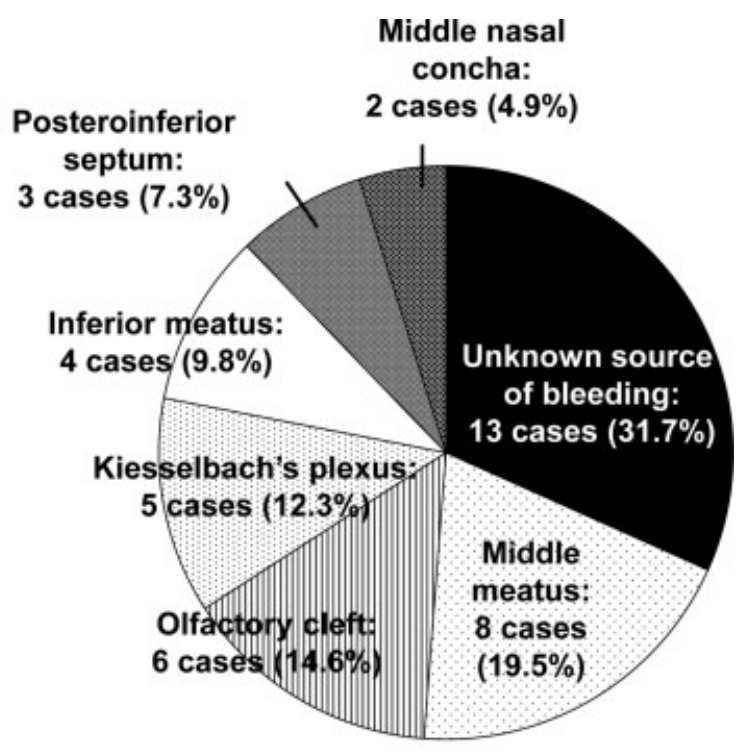

B

Fig. 5 Hospitalization cases. (A) Reason for hospitalization. The most common reason for hospitalization was difficulty in controlling the bleeding. (B) Site of bleeding in hospitalization cases. Unknown source of bleeding was the most common. 
There were $53.7 \%$ cases of after-hour admission of hospitalization cases (22/41 cases). Twelve of those cases involved initial bleeding, whereas 10 cases involved rebleeding. The most common reason for hospitalization was difficulties with hemostasis at $61.0 \%$ (25/41 cases) (-Fig. 5A). There were $48.8 \%$ cases of rebleeding (20/41 cases).

Furthermore, $75.0 \%$ cases had underlying conditions (31/41 cases). The most common underlying condition was hypertension at $39.0 \%$ ( $16 / 41$ cases), followed by heart disease at 31.7\% (13/41 cases) and diabetes at 17.0\% (7/41 cases). Impaired liver function and cerebrovascular disorders were noted in $7.3 \%$ of cases (3/41 cases each) (including overlapping cases). Moreover, $43.9 \%$ cases were using antithrombotic agents (18/41 cases). Seven of these cases discontinued the use of antithrombotic agents after the treatment of epistaxis, and five cases involved rebleeding. Compared with the total number of epistaxis cases, the number of patients with underlying conditions was high.

The most common site of bleeding was unknown in 31.7\% (13/41) cases, followed by the middle meatus in 19.5\% (8/41) and the olfactory cleft in 14.6\% (6/41) cases ( - Fig. 5B).

The method of the initial hemostasis was electrocoagulation in $46.3 \%$ (19/41) cases, compression with the nonabsorbent material in $31.7 \%(13 / 41)$ cases, and compression with the absorbent material in $7.3 \%$ (3/41) cases. Furthermore, $12.2 \%$ cases were observed without treatment (5/41 cases), $24.4 \%$ cases were treated with a rigid endoscope (10/41 cases), and 9.8\% cases were operated under general anesthesia (4/41 cases). For two of these cases, the site of bleeding could not be identified due to deviated septum, and electrocoagulation was performed after septoplasty to treat rebleeding where hemostasis was difficult. For the other two cases, general anesthesia was required due to developmental disabilities, and only electrocoagulation was performed. There were no cases of embolization or ligation.

\section{Discussion}

We clinically examined initial bleeding, rebleeding, and hospitalization of idiopathic epistaxis during the past 8 years.

\section{Patient Backgrounds}

As was found in past reports, the largest percentage of patients was in their 70s. Many people in this age group might have underlying conditions that could lead to bleeding. ${ }^{9,10}$ There were more men, which was the same as in the past reports. $6,7,9,11,12$ Likely reasons for more men suffering with epistaxis are work-related stress, more opportunities to drink and smoke, ${ }^{9,13-15}$ and female hormones providing mucosal protective effects. ${ }^{14,16}$

Winter had the highest number of cases, with summer having the smallest number of cases. This trend was consistent with past reports. ${ }^{7-9,13,17,18}$ This was likely related to irritation of the nasal mucosa caused by upper respiratory tract infection and climatic conditions such as temperature difference between indoors and outdoors and fluctuations in blood pressures. It has been reported that epistaxis tends to occur at night or while patients are sleeping ${ }^{12}$ and that blood pressure tends to fluctuate upon waking, ${ }^{19}$ which could be the reason for the high number of after-hour visits.

\section{Underlying Conditions}

In the present study, the ratios of hypertension, heart diseases, and use of antithrombotic agents were especially high. Hypertension was high in past reports as well ${ }^{7,9,13-15,20}$ and is an important risk factor of epistaxis and rebleeding. In addition to hypertension, heart diseases, diabetes, and hepatic diseases have been topics of discussion in several reports. ${ }^{7,20}$ There are also reports of the use of antithrombotic agents being a risk factor for epistaxis. ${ }^{13,21,22}$ It is possible that diseases that weaken blood vessels, diseases that require antithrombotic agents for treatment, and diseases that cause abnormal coagulation are involved with epistaxis. The impact of arteriosclerosis on weakening of blood vessels has also been reported. ${ }^{10}$ Risk factors for arteriosclerosis include hyperlipidemia, hypertension, diabetes, habitual smoking, obesity, being male, postmenopausal female, family history, and stress, ${ }^{14}$ which are consistent with the findings of the present study.

Risk factors for rebleeding for which significant differences were noted in the present study were heart diseases, impaired liver function, and the use of antithrombotic agents. There is no consensus on the risk of antithrombotic agents causing rebleeding, and papers we found had mixed reports. ${ }^{1,23-25}$ Presently, cases that used antithrombotic agents constitute $28.5 \%$ of the total, which is similar to past reports. ${ }^{1,9,20}$ But the rate of rebleeding was significantly higher in the present study at $60.6 \%$, compared with 20 to $40 \%$ in the past reports, ${ }^{1,9,20}$ which was considered to be a risk factor for rebleeding. Cases in which the antithrombotic agent was discontinued after the treatment of the initial hemostasis experienced significantly more rebleeding, which appeared to be due to selecting cases of bleeding that required the discontinuation of drugs.

We were unable to locate any reports of impaired liver function as a risk factor for rebleeding in the literature. In the present impaired liver function cases, despite using electrocoagulation for the site of bleeding during the initial examination, half of the cases experienced rebleeding. Abnormal coagulation caused by impaired liver function likely led to mucosal disorder during cauterization, which led to rebleeding.

\section{Site of Bleeding}

The Kiesselbach plexus is often reported to be the most common site for epistaxis. ${ }^{1,9,11,12,20}$ However, in cases of rebleeding and hospitalization, bleeding from the Kiesselbach plexus is considered to be less common. ${ }^{1,711,13-15,22}$ In our study, $75.0 \%$ of the epistaxis cases had bleeding from the Kiesselbach plexus, but the ratio of bleeding from the Kiesselbach plexus was low for rebleeding cases and hospitalization cases, and bleeding from the middle meatus, the olfactory cleft, and unknown source increased. The site of bleeding in refractory epistaxis includes the sphenopalatine artery, the descending palatine artery (the posterior end of the inferior nasal concha, the posterior end of the inferior meatus, and the middle meatus), and the anterior and posterior ethmoidal arteries (the 
canopy of middle nasal concha and the olfactory $)^{13,26}$. Rupture of carotid artery pseudoaneurysms associated with paranasal fungus, such as Aspergillus, can lead to severe epistaxis, which could be life-threatening. ${ }^{27}$ These sites of bleeding are difficult to identify, and in cases where the site of bleeding could not be identified during the initial treatment, the incidence of rebleeding is high. ${ }^{13}$ It has been reported that the use of a rigid endoscope reduced the incidence of rebleeding in cases of bleeding from sites other than the Kiesselbach plexus. ${ }^{28}$ If the site of bleeding cannot be confirmed with anterior rhinoscopy, both flexible and rigid endoscopes should be used and the possibility of refractory epistaxis should be kept in mind.

\section{Methods of Hemostasis}

Electrocoagulation was the most commonly used method of hemostasis. Although the use of a rigid endoscope was not high during the initial hemostasis ( $10.4 \%, 64 / 615$ cases), among cases of hemorrhage from the Kiesselbach plexus, 453 cases (excluding eight cases) achieved hemostasis upon confirming the site of bleeding with anterior rhinoscopy. There were $30.4 \%$ cases of after-hour visits where the use of a rigid endoscope was not possible (187/615 cases), which lowered the number of cases with a rigid endoscope. Although it is difficult to use a rigid endoscope for all cases, accurately identifying the site of bleeding and performing electrocoagulation would prevent rebleeding. For rebleeding cases, compression was commonly used during the initial hemostasis. It has been reported that when electrocoagulation was performed during the initial treatment, rebleeding was rare, but in cases where the site of bleeding was unclear or gauze compression was used, rebleeding was common, ${ }^{1,7,13,15,23,29-31}$ which was consistent with the present study.

\section{Hospitalization Cases}

A common reason for hospitalization was difficulty with hemostasis, and the site of bleeding was often unknown. In other reports, the Kiesselbach plexus was often not the source of bleeding in hospitalized cases. ${ }^{1,7,13}$ As long as the field of view and operability can be secured, hemostasis can be achieved with relative ease; however, other sites of bleeding are difficult to identify, and cases of rebleeding and difficulties with hemostasis increase. This likely led to hospitalization. In recent years, rigid endoscope use has become more common and endoscopic surgery techniques for the nose and sinuses have undergone improvements. This led to a method of identifying the point of bleeding using a rigid endoscope and performing electrocoagulation, and a method of coagulating the sphenopalatine artery with clipping. ${ }^{6,13}$ There were four cases where hemostasis was achieved under general anesthesia. For all the four cases, the site of bleeding could be identified, and there was no case of ligation of the maxillary artery or arterial embolization.

\section{Conclusions}

- We examined 615 cases of idiopathic epistaxis that were treated at our department over 8 years.
- Most cases were in their 70s, and there were more men than women. The time of visits peaked in January, indicating that many patients visited a medical institution during winter. The most common treatment for hemostasis was electrocoagulation.

- The most common underlying disease was hypertension. Statistically significant risk factors for rebleeding were heart diseases, impaired liver function, and the use of antithrombotic agents.

- During the initial bleeding, the Kiesselbach plexus was the most common site of bleeding, but the ratio of the middle meatus, the olfactory cleft, and unknown source increased during rebleeding. Thus, careful observation of the nasal cavity including the use of a rigid endoscope is necessary.

- In many of the cases that were hospitalized, the reason for hospitalization was difficulties with hemostasis. The site of bleeding was also often a site other than the Kiesselbach plexus.

Conflict of Interest

None declared.

\section{References}

1 Fuji S, Hirai M, Shigehara A, Nakai K, Orita Y. Risk factors for rebleeding after the treatment of epistaxis. Nippon Jibiinkoka Gakkai Kaiho 2016;119(08):1117-1126

2 Willems PWA, Farb RI, Agid R. Endovascular treatment of epistaxis. AJNR Am J Neuroradiol 2009;30:1637-1645

3 Morgan DJ, Kellerman R. Epistaxis: evaluation and treatment. Prim Care 2014;41(01):63-73

4 Kilty SJ, Al-Hajry M, Al-Mutairi D, et al. Prospective clinical trial of gelatin-thrombin matrix as first line treatment of posterior epistaxis. Laryngoscope 2014;124(01):38-42

5 Kucik CJ, Clenney T. Management of epistaxis. Am Fam Physician 2005;71(02):305-311

6 Ishinaga H, Kato A, Yamada H. Clinical study of severe epistaxis treated by surgical therapy. Pract Otorhinolaryngol (Basel) 1999; 92(04):363-366

7 Nishikawa H, Hidaka H, Kudou T, Kobayashi T. A clinical study of 203 hospitalized epistaxis patients. Jpn J Rhinol 2012;51(04): 481-488

8 Yukitatsu Y, Tsuzuki K, Takebayashi H, Sakagami M. Clinical study of 1,515 patients presenting with epistaxis over the last 6 years. ORL J Otorhinolaryngol Relat Spec 2016;78(04):232-240

9 Homma Y, Hashimoto S, Ono M, et al. Clinical study of epistaxis patients. Oto-Rhino-Laryngol Tokyo 2008;51:442-446

10 Takano S, Uchimura K, Shigi K, et al. Retrospective study of epistaxis. Pract Otol 1999;92(07):721-724

11 Hasegawa T, Takegoshi H, Kikuchi S, Iinuma T. A statistical analysis of epistaxis between outpatients and inpatients [in Japanese]. Nippon Jibiinkoka Gakkai Kaiho 2004;107(01):18-24

12 Kodama H, Shido F, Kataura A. Statistical analysis of patients with epistaxis treated at Sapporo Medical College Hospital. Oto-RhinoLaryngol Tokyo 1987;30:567-574

13 Masuda Y, Nakanoboh M, Matsunaga T, Tanabe T, Kitahara S. A retrospective review of hospitalized patients with epistaxis. Pract Otol 2000;93(08):629-634

14 Umemoto S, Tateyama K, Watanabe T, Hirano T, Suzuki M. A clinical study of 206 hospitalized patients with epistaxis. Jpn J Rhinol 2019;58(02):243-249

15 Nario K, Miyahara H, Sasai H, et al. A clinical study of hospitalized epistasis patients. Jpn J Rhinol 2008;47(01):1-7

16 Daniell HW. Estrogen prevention of recurrent epistaxis. Arch Otolaryngol Head Neck Surg 1995;121(03):354 
17 Nunez DA, McClymont LG, Evans RA. Epistaxis: a study of the relationship with weather. Clin Otolaryngol Allied Sci 1990;15 (01):49-51

18 Manfredini R, Gallerani M, Portaluppi F. Seasonal variation in the occurrence of epistaxis. Am J Med 2000;108(09):759-760

19 Minami J, Ishimitsu T, Matsuoka H. Beneficial effects of combination therapy with losartan and low-dose hydrochlorothiazide in the treatment of essential hypertension [in Japanese]. Nippon Jinzo Gakkai Shi 2005;47(08):864-869

20 Kamatani M, Nakamura K, Nagata T, et al. Patients visiting the emergency department while exhibiting epistasis with neurally mediated syncope. Jpn J Rhinol 2019;58(04):712-718

21 Iguchi Y, Yao K, Nishiyama K, Satou K. A clinical study of surgical treatments of epistaxis. Pract Otol 2003;96(06):541-547

22 Lubianca-Neto JF, Bredemeier M, Carvalhal EF, et al. A study of the association between epistaxis and the severity of hypertension. Am J Rhinol 1998;12(04):269-272

23 Vergara Hernández J, Ordóñez Ordóñez LE. Surgical versus nonsurgical treatment of posterior epistaxis [in Spanish]. Acta Otorrinolaringol Esp 2006;57(01):41-46
24 Srinivasan V, Patel H, John DG, Worsley A. Warfarin and epistaxis: should warfarin always be discontinued? Clin Otolaryngol Allied Sci 1997;22(06):542-544

25 Ota H, Takano Y, Kawasaki M. A study of 318 epistaxis cases. Pract Otol 2010;103(05):427-430

26 Ishida R, Yamada H, Nishii S, Tokuriki T, Ishinaga H. Epistaxis surgery. Jpn J Rhinol 2002;41(04):345-348

27 Uno K, Asaka D, Okano S, et al. A case of internal carotid artery rapture caused by acute invasive fungal sinusitis. Oto-RhinoLaryngol Tokyo 2012;55:28-35

28 Iimura J, Hatano A, Ando Y, et al. Study of hemostasis procedures for posterior epistaxis. Auris Nasus Larynx 2016;43(03):298-303

29 Ando Y, limura J, Arai S, et al. Risk factors for recurrent epistaxis: importance of initial treatment. Auris Nasus Larynx 2014;41(01): 41-45

30 Umapathy N, Quadri A, Skinner DW. Persistent epistaxis: what is the best practice? Rhinology 2005;43(04):305-308

31 Bent JP III, Wood BP. Complications resulting from treatment of severe posterior epistaxis. J Laryngol Otol 1999;113(03): 252-254 